\title{
Mechanisms of reduced pulmonary function after a saturation dive
}

\author{
E. Thorsen, K. Segadal, B.K. Kambestad
}

\begin{abstract}
Mechanisms of reduced pulmonary function after a saturation dive. E. Thorsen, $K$. Segadal, B.K. Kambestad. OERS Journals Ltd 1994.

ABSTRACT: Deep saturation diving has been shown to have prolonged effects on pulmonary function. We wanted to assess the relative contribution of various factors that could contribute to these effects.

Pulmonary function was, therefore, measured before and after 17 different saturation diving operations to depths of $5-450 \mathrm{~m}$ of sea water, corresponding to absolute pressures of 0.15-4.6 MPa. Four to fifteen divers participated in each operation. The measurements included static and dynamic lung volumes and flows, transfer factor of the lungs for carbon monoxide (TLCO), and closing volume. The dives were characterized by the cumulative hyperoxic and hyperbaric exposures, and the load of venous gas microemboli encountered during decompression was measured in 41 divers in three dives to $0.25,1.2$ and 3.7 MPa.

TLCo was reduced by $8.3 \pm 7.0 \%$ mean \pm SD after the dives, this correlated with cumulative hyperoxic exposure and load of venous gas microembolism, independently of each other. Closing volume was increased and forced mid-expiratory flow rate reduced, in correlation with cumulative hyperoxic exposure. An increase in total lung capacity correlated with cumulative hyperbaric exposure.

We conclude that hyperoxia, hyperbaria, and venous gas microembolism all contribute to the changes in pulmonary function after a single saturation dive, and all may explain some of the long-term effects of diving on pulmonary function. Eur Respir J., 1994, 7, 4-10.
\end{abstract}

Norwegian Underwater Technology Centre A/S, Gravdalsveien 255, N-5034 Ytre Laksevåg, Norway.

Correspondence: E. Thorsen

NUTEC, P.O. Box 6

N-5034 Ytre Laksevåg

Norway

Keywords: Decompression

diving

hyperbaria

hyperoxia

lung function

venous gas microembolism

Received: February 91993

Accepted after revision August 81993
Saturation diving is a specific diving technique in common use for diving operations to depths of $50 \mathrm{~m}$ of sea water and deeper, corresponding to absolute pressures of $\geq 0.6 \mathrm{MPa}(1 \mathrm{MPa}=1,000 \mathrm{kPa}=10 \mathrm{bar})$. The divers are compressed to the pressure corresponding to the working depth in a hyperbaric chamber complex, from which they are transferred to and from the in-water worksite in a diving bell. During the bottom or isopression phase, the partial pressures of the inert gases of the atmosphere equilibrate with the body tissues, which become saturated with the inert gases. During the decompression phase, the inert gases must be eliminated from the tissues. To avoid excessive microbubble formation and decompression sickness, the decompression rate is limited to $0.24-0.30$ $\mathrm{MPa} \cdot \mathrm{day}^{-1}$. The inert gas of the atmosphere is usually helium, to reduce the density of the breathing gas and thereby the work of breathing. The partial pressure of oxygen $\left(\mathrm{PO}_{2}\right)$ is raised to $35-40 \mathrm{kPa}$ during the isopression phase, and to $60-100 \mathrm{kPa}$ during the in-water working periods to ensure oxygenation; and to $50-60 \mathrm{kPa}$ during decompression to facilitate inert gas elimination, (fig. 1). A typical saturation diving operation in the oil fields of the North Sea lasts for 2-3 weeks, and there may be 12 to 16 divers participating in the operation and living in the hyperbaric chamber system at the same time.

A transient reduction in transfer factor for carbon monoxide (TLCO), and an increase in closing volume and static lung volumes have been demonstrated immediately after deep experimental saturation dives to depths corresponding to absolute pressures of $3.1-4.6 \mathrm{MPa}$ [1-3]. Cross-sectional studies of divers [4-6], and a longitudinal follow-up of pulmonary function after deep saturation dives [7], have indicated development of small airways dysfunction related to diving exposure. These symptoms may be caused by toxic effects of oxygen [8], and by venous gas microemboli, generated during the decompression and filtered in the pulmonary circulation [9-11]. Other factors, such as toxic effects of pollutants in the confined space of hyperbaric chambers and pressure per se, may also contribute.

In this study, the acute effects of operational saturation diving in the North Sea to pressures up to $2.2 \mathrm{MPa}$ were studied, and compared with the effects of experimental deep and shallow saturation dives, enabling us to analyse the effects of different exposure variables over the full range of operational pressures, up to 4.6 MPa. 


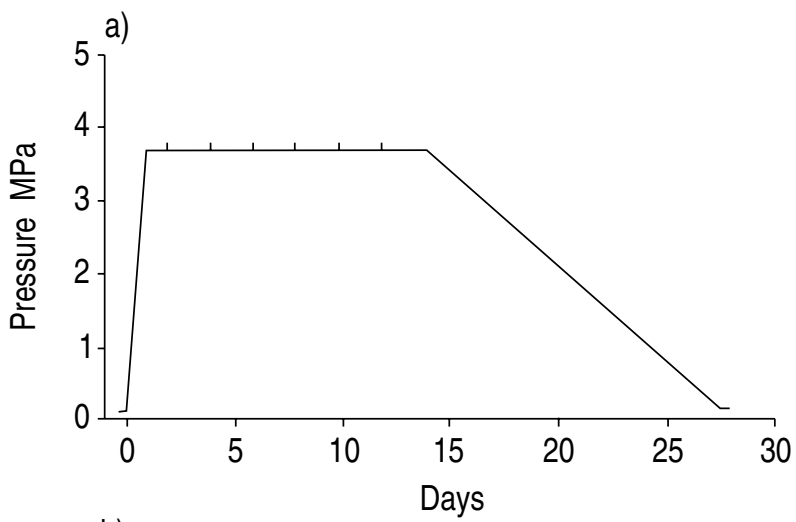

b)

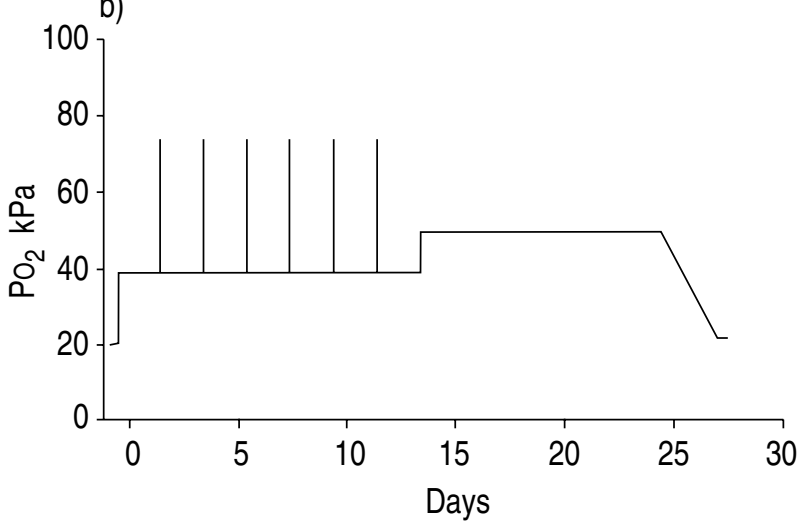

Fig. 1. - Diagramatic representation of the profile of exposure: a) to absolute pressure and b) to partial pressure of oxygen during a saturation diving operation.

\section{Methods}

The dives

Seventeen different saturation diving operations to pressures of $0.15-4.6 \mathrm{MPa}$ were studied, (table 1). The results of the experimental deep dives to pressures $\geq 3.1 \mathrm{MPa}$ have been published previously [3, 9]. There were 4 to 15 divers participating in each operation. The atmospheres were helium and oxygen mixtures in all dives to pressures of $\geq 1.2 \mathrm{MPa}$. In the dive to $0.25 \mathrm{MPa}$ the atmosphere was a mixture of helium, nitrogen and oxygen, and in the dive to $0.15 \mathrm{MPa}$ a mixture of nitrogen and oxygen. The $\mathrm{PO}_{2}$ was $35-40 \mathrm{kPa}$ during the isopression phases, and 50-60 kPa during the decompression phases, but never exceeded $21 \%$ of total pressure. The duration of the isopression phase was 3.5 to 27.75 days, and the duration of the decompression phase was 0.25 to 18 days. The mean rate of decompression was 0.24-0.30 MPa.day ${ }^{-1}$. Eight dives were operational saturation dives in the North Sea to pressures of 1.2-3.1 $\mathrm{MPa}$. The other nine dives were simulated in the hyperbaric chamber complex at the Norwegian Underwater Technology Centre at pressures of 0.15-4.6 MPa. Hyperbaric welding operations in dry habitats were performed in six of the dives. In four of these, the welder divers were breathing through masks with a separate gas supply during the welding operations, whilst in the other two they were breathing freely in the welding habitat.

\section{The divers}

Ninety six experienced saturation divers participated in the operational and experimental dives to pressures of $\geq 1.2 \mathrm{MPa}$, whereas 14 subjects without diving experience participated in the experimental dives to 0.15 and $0.25 \mathrm{MPa}$. Six divers took part in three different dives, and 10 divers took part in two different dives. The divers median age was 32 yrs (range 23-49 yrs), height 179 $\mathrm{cm}$ (range 167-193 cm), and body mass $79 \mathrm{~kg}$ (range 64-96 kg). Twenty-eight divers were smokers. Exsmokers were classified as nonsmokers, if they had stopped smoking for more than one year, otherwise as smokers. Twenty two divers were experienced welder divers, 16 of whom carried out the welding operations in the two dives in which welding was performed without respiratory protection. All subjects gave written informed consent, and the protocol for the medical and physiological monitoring of the dives had been approved by the Regional Ethics Review Committee.

\section{Pulmonary function}

Dynamic lung volumes and flows were measured by at least three satisfactory forced expiratory manoeuvres started from total lung capacity in the sitting position.

Table 1. - Characteristics of the hyperbaric exposures

\begin{tabular}{|c|c|c|c|c|c|c|c|}
\hline $\begin{array}{l}\text { Pressure } \\
\mathrm{MPa}\end{array}$ & $\begin{array}{l}\text { Saturation } \\
\text { diving } \\
\text { operations } \\
n\end{array}$ & $\begin{array}{c}\text { Divers } \\
n\end{array}$ & $\begin{array}{c}\text { Decompression } \\
\text { rate } \\
\mathrm{MPa} \cdot \mathrm{day}^{-1}\end{array}$ & $\begin{array}{c}\mathrm{Po}_{2} \text { isopression } \\
\text { phase } \\
\mathrm{kPa}\end{array}$ & $\begin{array}{c}\mathrm{Po}_{2} \text { decompression } \\
\text { phase } \\
\mathrm{kPa}\end{array}$ & $\begin{array}{c}\text { Duration } \\
\text { isopression } \\
\text { phase } \\
\text { days }\end{array}$ & $\begin{array}{c}\text { Duration } \\
\text { decompression } \\
\text { phase } \\
\text { days }\end{array}$ \\
\hline 0.15 & 1 & 6 & 0.125 & 21 & 30 & 27.75 & 0.25 \\
\hline 0.25 & 1 & 8 & 0.075 & $40-50$ & 50 & 25 & 2 \\
\hline 1.2 & 2 & 20 & 0.24 & 35 & $40-50$ & $9-18$ & 3.5 \\
\hline 1.55 & 2 & 15 & 0.27 & 40 & 50 & $8-18.5$ & 5.5 \\
\hline 2.2 & 3 & 28 & 0.24 & 40 & 50 & 15.5 & 8.5 \\
\hline 3.1 & 2 & 16 & $0.24-0.30$ & $35-40$ & $50-60$ & $3.5-10$ & $9-12$ \\
\hline 3.6 & 2 & 15 & $0.27-0.30$ & 40 & $50-60$ & $5-14$ & 11 \\
\hline 3.7 & 3 & 18 & 0.27 & 40 & 50 & $5-14$ & 13 \\
\hline 4.6 & 1 & 6 & 0.25 & 40 & 50 & 12 & 18 \\
\hline
\end{tabular}


Forced vital capacity (FVC), forced expired volume in one second $\left(\mathrm{FEV}_{1}\right)$ and peak expiratory flow rate $(\mathrm{PEF})$ were taken as the highest readings obtained. The forced mid-expiratory flow rate $\left(\mathrm{FEF}_{25-75 \%}\right)$, mean forced expiratory flow rate between 75 and $85 \%$ of FVC expired $\left(\mathrm{FEF}_{75-85 \%}\right)$, and forced expiratory flow rates at 50 and $75 \%$ of FVC expired $\left(\mathrm{FEF}_{50 \%}\right.$, and $\left.\mathrm{FEF}_{75 \%}\right)$, were taken as the highest readings from flow-volume loops with FVC not differing by more than $5 \%$ from its highest value [12]. Transfer factor for carbon monoxide (TLCO) was measured by using the single-breathholding method [12]. Effective alveolar volume was measured simultaneously by helium dilution, and transfer factor of carbon monoxide per unit alveolar volume calculated (KCO). Multibreath nitrogen washout technique was used to measure functional residual capacity (FRC). By combining FRC with the measurements of expiratory reserve volume and inspiratory vital capacity, total lung capacity and residual volume (RV) were then calculated. Closing volume $(\mathrm{CV})$ and the slope of phase III of the singlebreath oxygen test $\left(\Delta-\mathrm{N}_{2}\right)$ were also measured [13]. All measurements were made using a Gould Model 1000 IV computerized lung function testing system (Gould Inc., Dayton, OH, USA). Volume and test gas calibrations were performed before each test using the automatic dynamic calibration procedure of the instrument, and the volume calibration was verified with a calibrated syringe, before and after each test, (Gould Calibration Syringe, $3.00 l$, Gould Inc., Dayton, OH, USA). The same instrument and calibration syringe were always used. On the predive examination, at least four weeks had elapsed since their last saturation dive. The pre-dive examinations were carried out 1-6 weeks before the dives, and the postdive examinations were carried out 1-3 days after the end of the decompression phase of the dives.

\section{Assessment of exposure}

Each dive was characterized by its pressure profile, including the duration of the compression, isopression and decompression phases, and the $\mathrm{Po}_{2}$ during the different phases as shown diagramatically in figure 1 . The conventional method for calculating the toxic pulmonary oxygen dose, the Unit Pulmonary Toxic Dose (UPTD) and the Cumulative Pulmonary Toxic Dose (CPTD), as introduced by CLARK and LAMBERTSEN [14], does not take into account exposure to a $\mathrm{PO}_{2}$ below $50 \mathrm{kPa}$, and is valid only for vital capacity as the lung function variable. It is therefore not applicable for calculating oxygen exposure in saturation diving operations. The cumulative hyperoxic exposure was therefore calculated for each diver according to the formula:

$$
\int\left[\mathrm{PO}_{2}(\mathrm{t})-21\right] d t
$$

which corresponds to the area enclosed by the curve showing $\mathrm{PO}_{2}$ as a function of time and a horizontal line at $\mathrm{PO}_{2}=21 \mathrm{kPa}$, (fig. 1b). The cumulative hyperoxic exposure in excess of 30 and $40 \mathrm{kPa}$ and CPTD were also calculated, since a threshold for $\mathrm{Po}_{2}$ resulting in lung function changes has been suggested $[14,15]$. Cumulative hyperbaric exposure was calculated in the same way. During the in-water activity, and welding activity, the $\mathrm{PO}_{2}$ in the breathing gas was $60-100 \mathrm{kPa}$ for periods of $2-6 \mathrm{~h}$ of the workshift, and the pressure varied by \pm 0.1 $\mathrm{MPa}$ relative to isopressure during these periods. This accounted for $<4 \%$ and $<1 \%$ of the cumulative hyperoxic and hyperbaric exposure, respectively.

In 41 divers who participated in dives to pressures of $0.25,1.2$ and 3.7 MPa, Doppler ultrasound monitoring for venous gas microemboli during decompression was performed as described previously [9]. Monitoring was carried out twice daily from peripheral veins and the pulmonary artery, with precordial positioning of the probe. It was done with the subjects at rest and after a standardized bout of limb movements. The sequence of monitoring from the different sites was also standardised. Bubble scores were classified according to the Spencer scale [16]. The accumulated load of venous gas microemboli was calculated, as the sum of bubble scores registered precordially after limb movements during decompression.

\section{Data processing and statistics}

The individual changes in the lung function variables were calculated, as the differences from the mean of the predive and postdive examinations. The results are given as the mean $\pm 1 \mathrm{sD}$. The differences between predive and postdive examinations were tested with two-tailed t-test. A p-value $<0.05$ was considered significant.

Simple correlation analysis was used to test for colinearity between the different exposure factors. Forward stepwise multiple regression analysis was used to find relevant correlations between the changes in the lung function variables and the subjects' characteristics (age, weight $\cdot$ height $^{-2}$, smoking habit), and the characteristics of the dives (cumulative hyperoxic exposure, cumulative hyperbaric exposure, decompression rate, welding). Smoking and welding, when performed without respiratory protection, were included as indicator variables being present or absent. The same analysis, including accumulated bubble score as an independent variable, was used for subjects in whom Doppler ultrasound monitoring was performed. Analyses with use of the cumulative hyperoxic exposure in excess of 30 and $40 \mathrm{kPa}$ and CPTD, and with cumulative hyperoxic exposure modelled as hyperbolic and exponential functions were also carried out.

\section{Results}

The changes in the lung function variables immediately after the dives are summarized in table 2 . The pattern of changes in the lung function variables, when including all of the dives, was as previously reported for deep saturation dives [3], with a significant reduction in TLCO and $\mathrm{KCO}$, and an increase in the static lung volumes and closing volume. A significant reduction in 
Table 2. - Mean changes and regression coefficients for exposure variables with significant correlations to the change in the lung function variables

\begin{tabular}{|c|c|c|c|c|c|c|}
\hline & $\begin{array}{c}\text { Mean } \\
\%\end{array}$ & $\begin{array}{c}\text { Cumulative } \\
\text { hyperoxic } \\
\text { exposure } \\
\mathrm{kPa} \cdot \text { days }^{-1}\end{array}$ & $\begin{array}{l}\text { Cumulative } \\
\text { hyperbaric } \\
\text { exposure } \\
\mathrm{MPa} \cdot \text { days }^{-1}\end{array}$ & $\begin{array}{l}\text { Accumulated } \\
\text { bubble score }\end{array}$ & Intercept & $\mathrm{R}^{2}$ \\
\hline$\Delta \mathrm{FVC}$ & $0.6 \pm 4.3$ & & & & & \\
\hline$\Delta \mathrm{FEV}_{1}$ & $0.4 \pm 4.8$ & & & & & \\
\hline$\Delta \mathrm{FEF}_{25-75 \%}$ & $-3.7 \pm 8.3 *$ & -0.015 & & & 3.49 & 0.09 \\
\hline$\triangle \mathrm{PEF}$ & $-1.7 \pm 8.7$ & & & & & \\
\hline$\Delta \mathrm{TLC}$ & $2.1 \pm 5.3 *$ & & $0.0007 *$ & & 0.50 & 0.14 \\
\hline$\Delta \mathrm{RV}$ & $6.4 \pm 14.0$ & & $0.0031 *$ & & -4.63 & 0.09 \\
\hline$\Delta \mathrm{CV}$ & $12.1 \pm 15.4 * *$ & $0.0022 * *$ & $0.020 *$ & & -4.20 & 0.40 \\
\hline \multirow[t]{2}{*}{$\Delta \mathrm{TLCO}^{\#}$} & $-8.3 \pm 7.0 * * *$ & $-0.018 * * *$ & & \multirow{3}{*}{$(-0.32)^{*}$} & -0.39 & 0.34 \\
\hline & & $(-0.019) * * *$ & & & $(-0.64)$ & $(0.46)$ \\
\hline \multirow[t]{2}{*}{$\Delta \mathrm{KCO}^{\#}$} & $-7.8 \pm 7.5 * * *$ & $-0.010 * * *$ & & & -0.37 & 0.32 \\
\hline & & $(-0.011)^{* * *}$ & & $(-0.42)^{*}$ & $(-1.59)$ & $(0.41)$ \\
\hline
\end{tabular}

\#: regression coefficients given in brackets are the results of the subgroup of divers in whom Doppler ultrasound monitoring during decompression was done $(\mathrm{n}=41) ; *: \mathrm{p}<0.05 ; * *: \mathrm{p}<0.01 ; * * *: \mathrm{p}<0.001$. FVC: forced vital capacity; $\mathrm{FEV}_{1}$ : forced expiratory volume in one second; $\mathrm{FEF}_{25-75 \%}$ : forced mid-expiratory flow rate; PEF: peak expiratory flow; TLC: total lung capacity; RV: residual volume; CV: closing volume; TLCO: transfer capacity of the lungs for carbon monoxide; KCO: carbon monoxide transfer coefficient.

$\mathrm{FEF}_{25-75 \%}$, which was not seen in the previous studies of deep dives [3], was now apparent. There were no significant changes in FVC and $\mathrm{FEV}_{1}$.

There was a weak correlation between cumulative hyperoxic exposure, cumulative hyperbaric exposure, and accumulated load of venous gas microemboli ( $\mathrm{r}=0.40$ to 0.54). All correlated strongly with maximal pressure $(\mathrm{r}=0.64$ to 0.86$)$. When maximal pressure was not included in the analysis, there was a positive relationship between the changes in static lung volumes and cumulative exposure to hyperbaria, a negative relationship between the change in $\mathrm{FEF}_{25-75 \%}$ and cumulative hyperoxic exposure, and a negative relationship between the changes in TLCO and $\mathrm{KCO}$ and cumulative hyperoxic exposure (table 2).
When maximal pressure was included in the analysis, it correlated positively with the changes in static lung volumes only. Decompression rate and welding were not significantly related to the changes in the lung function variables in the multiple regression analysis. The relationships between maximal pressure and change in TLCO, and cumulative hyperoxic exposure and change in TLCO, are shown in figures 2 and 3. Better fits to the observed data were not obtained when using cumulative hyperoxic exposure in excess of 30 and $40 \mathrm{kPa}$ and CPTD, or when modelling the hyperoxic exposure as hyperbolic or exponential functions. The changes in the lung function variables did not show any correlation with any of the subjects' characteristics.

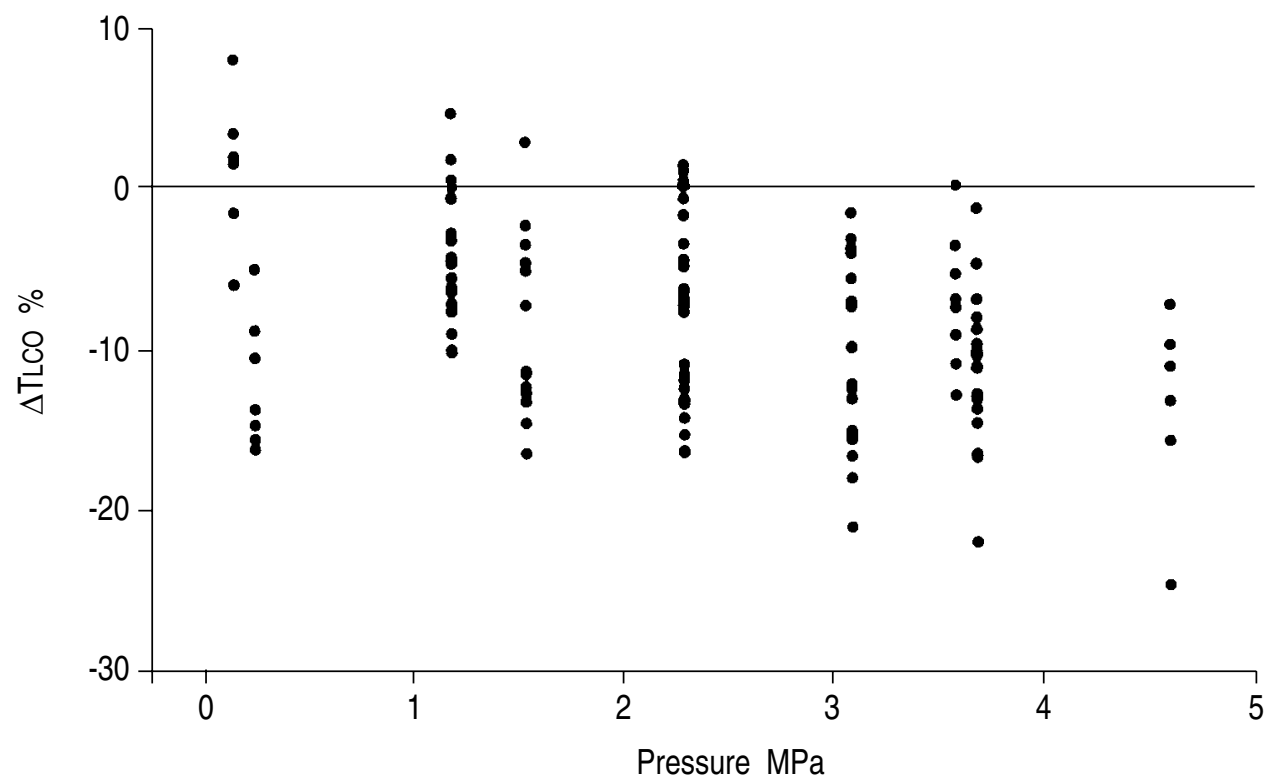

Fig. 2. - Individual changes in ThCo in relation to maximal pressure of the dives. TLCo: transfer capacity of the lungs for carbon monoxide. 


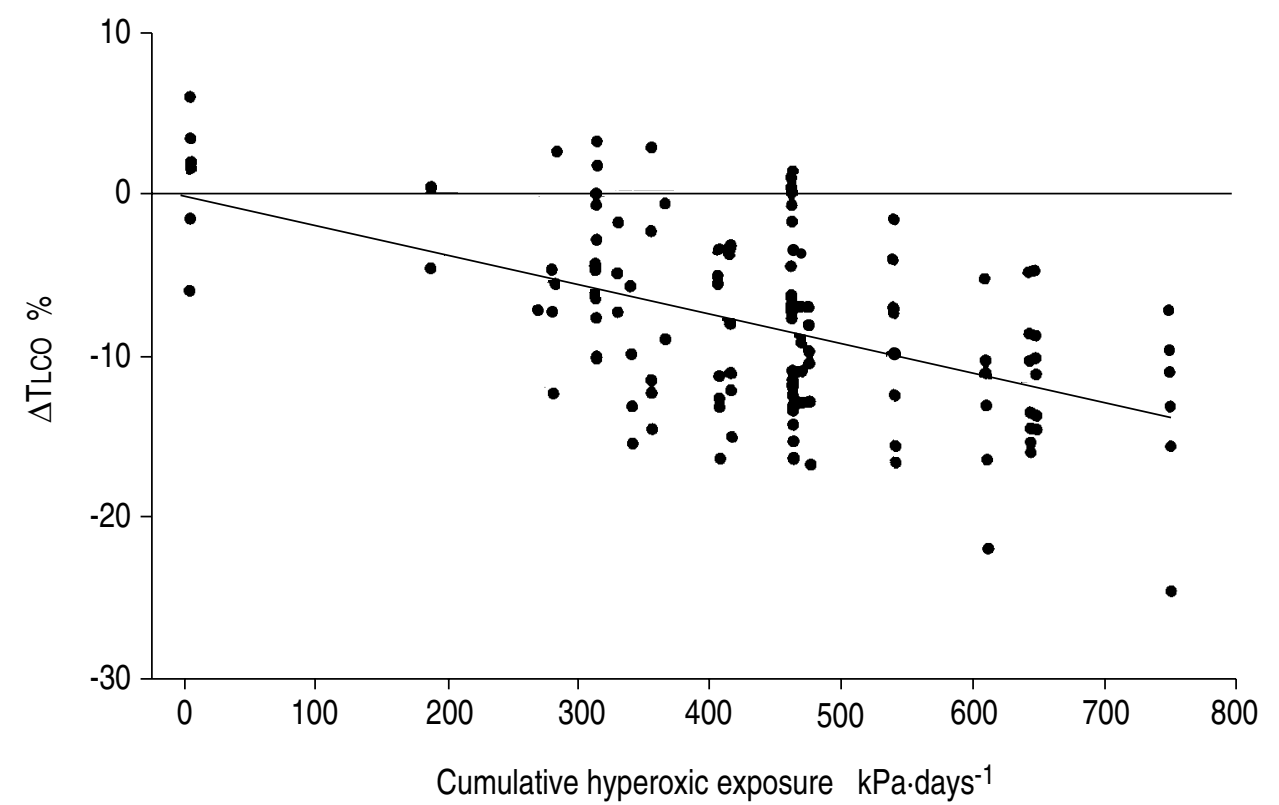

Fig. 3. - Individual changes in TLCo in relation to cumulative hyperoxic exposure. TLCo: transfer capacity of the lungs for carbon monoxide.

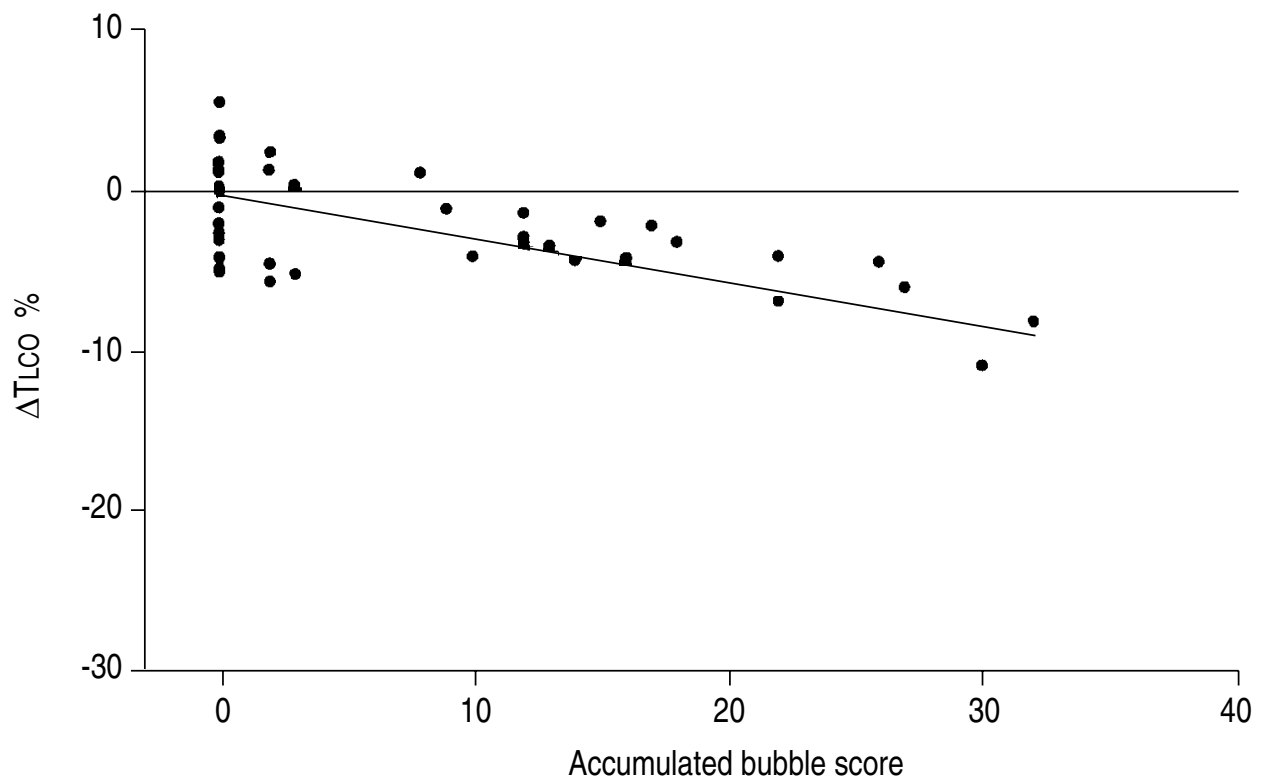

Fig. 4. - Individual changes in TLCo in relation to load of venous gas microemboli, measured as accumulated bubble score during decompression, after correction for the effect of cumulative hyperoxic exposure. TLCO: transfer capacity of the lungs for carbon monoxide.

In the 41 subjects in whom the load of venous gas microemboli was assessed, the load of venous gas microemboli was correlated with the decrease in TLCO, independent of the relationship to cumulative hyperoxic exposure (table 2 and fig. 4).

\section{Discussion}

It is known that in saturation diving there is an exposure to various factors that are potentially harmful to the lungs. In previous studies, it has not been possible to assess the relative contribution of these exposures to the effects on pulmonary function, due to a limited number of observations and a small range of variation in the dose of the various exposure factors. We have supplemented our previous experience from deep experimental saturation dives with studies of saturation dives over the full range of operational pressures, and with experimental saturation dives in the very shallow range of pressures of 0.15 and $0.25 \mathrm{MPa}$.

The pattern of changes in pulmonary function, as seen after deep saturation dives, was confirmed. These changes could be influenced by the previous saturation dive performed, since the recovery time can be as long as 4-6 weeks $[1,3]$. The effects measured in the professional saturation divers may, therefore, be different from the effects measured in the subjects diving to 0.15 and 0.25 
$\mathrm{MPa}$, who had no diving experience, and whose lung function was unaffected by previous diving and possible adaptive mechanisms to hyperbaria and hyperoxia. However, on the predive examination, at least four weeks had elapsed since the divers' last saturation dive.

The diving exposure is multifactorial, and different exposure factors are interrelated. Cumulative hyperbaric exposure and cumulative hyperoxic exposure are both a function of the duration of the dive. Because of the limitations in the decompression rate, the duration of the dive will also be a function of maximal pressure. The exposure variables, cumulative hyperoxic and hyperbaric exposure, and load of venous gas microemboli, were related, and all of them were strongly correlated with maximal pressure. It is, therefore, a possibility that the effects have been ascribed to exposure variables that are not representative of the basic mechanisms for the effects, and unknown factors which are also related to maximal pressure may operate. However, the shallow dive to $0.25 \mathrm{MPa}$ with the same cumulative oxygen exposure as one of the dives to 3.7 $\mathrm{MPa}$, demonstrated a primary effect of hyperoxia. In another study [10], a primary effect of venous gas microemboli on TLCo was demonstrated, indicating that these two exposure factors have effects by separate mechanisms.

Maximal pressure is an important characteristic of a dive, but there are, as yet, no studies indicating that pressure per se has any effect on pulmonary function, except for pure mechanical effects related to gas density [17]. The increase in static lung volumes seen after the dives could indicate an adaptation or training effect of respiratory muscles, due to the increased work of breathing in an atmosphere of high gas density. However, a reduction in $\mathrm{RV}$, rather than an increase, would then be expected [18]. An increase in the static lung volumes, including $\mathrm{RV}$, and reduction in maximal expiratory flow rates could, however, also indicate a loss of pulmonary elastic tissue and an emphysematous lesion, as seen in divers postmortem [19].

Maximal pressure is, on the other hand, determining the quantity of inert gases dissolved in the tissues, which has to be eliminated during the decompression phase. Several studies have shown that venous gas microemboli are formed during decompressions according to accepted decompression tables [16]. There is a large interindividual variation in the liability for bubble formation [9]. The correlation between bubble grade and clinical decompression sickness is weak [16], and the detection of bubbles by Doppler-ultrasound monitoring is not a good predictor of decompression sickness [20]. A possible explanation for this, is that only circulating and not stationary bubbles are detected in the tissues, and that monitoring can be carried out over a limited period only; the technique does not allow continuous monitoring. The circulating microbubbles are filtered in the pulmonary circulation. Animal studies have shown gas exchange abnormalities [11], and structural vascular changes [21] with venous infusion of air microbubbles. Our results indicate that this mechanism also affects pulmonary function after a saturation dive, in that there was a significant relationship between accumulated bubble score and the reductions in TLCO and KCO. This is con- sistent with the study of DuJIC et al. [10], showing a correlation between the reduction in TLCO and bubble scores after air dives to a pressure of $0.55 \mathrm{MPa}$, with $25 \mathrm{~min}$ bottom time and 19 min decompression time.

The strongest correlation was found between the change in the lung function variables and the hyperoxic exposure. The hyperoxic exposure was not, however, calculated in the traditional manner. The shallow saturation dive at $0.25 \mathrm{MPa}$ with $\mathrm{Po}_{2}$ of $40-50 \mathrm{kPa}$ for 28 days during which no venous gas microemboli were demonstrated, showed significant changes in pulmonary function. The traditional method for calculating toxic pulmonary oxygen exposure is derived from the dose-response relationship for vital capacity changes [14], and it is assumed that a $\mathrm{PO}_{2}$ of less than $50 \mathrm{kPa}$ does not have toxic effects on the lungs, detectable by vital capacity changes.

When calculating the oxygen exposure, according to the traditional UPTD and CPTD units, the dose would have been near zero, accounting only for the short intervals of in-water activity. The concept of UPTD is still valid, in that no changes in vital capacity were demonstrated after the dives, but other lung function variables may be more sensitive to toxic effects of oxygen. There was a significant correlation between cumulative hyperoxic exposure and the change in maximal expiratory flow rates, CV and TLco. The characteristic hyperbolic or exponential dose-response relationship was, however, not evident within the range of hyperoxic exposure in the dives studied. This could be due to the relatively low $\mathrm{Po}_{2}$ and the long duration of the exposures, during which adaptive mechanisms may evolve.

The results are in agreement with the study of SUZUKI et al. [2], in which there was a larger reduction in TLCO after a deep dive to $3.1 \mathrm{MPa}$ with a $\mathrm{Po}_{2}$ of $49.5 \mathrm{kPa}$ during decompression, compared with a dive to $3.3 \mathrm{MPa}$ with a $\mathrm{Po}_{2}$ Of $42 \mathrm{kPa}$ during decompression. In a study by CLARK et al. [22], there was a significant reduction in maximal expiratory flow rates and an increase in $\Delta-\mathrm{N}_{2}$ after exposure to oxygen at 3.0 ATA for $3.5 \mathrm{~h}$. No changes in vital capacity were predicted or demonstrated after that dive, and TLCO was unchanged.

In the confined spaces of hyperbaric chambers and, especially welding habitats, toxic pollutants may accumulate that are not absorbed by the scrubber systems. Welding operations are now taking place with the divers breathing through masks with a separate gas supply, so that exposure to contaminants is avoided. We found no correlation between the changes in lung function variables and welding, but measurements were not taken in direct relation to the welding exposure.

Further studies are necessary to determine the doseresponse characteristics with respect to lung function variables other than vital capacity. Maximal expiratory flow rates, CV and TLCo are apparently more sensitive to toxic hyperoxic effects than vital capacity. Diving procedures should be improved to reduce hyperoxic exposure and decompression stress.

Acknowledgements: This study was supported by Statoil, Norsk Hydro a.s., Saga Petroleum A/S and The Norwegian Petroleum Directorate. 


\section{References}

1. Cotes JE, Davey IS, Reed JW, Rooks M. - Respiratory effects of a single saturation dive to $300 \mathrm{~m}$. Br J Ind Med 1987; 44: 76-82.

2. Suzuki S, Ikeda T, Hashimoto A. - Decrease in the single-breath diffusing capacity after saturation dives. Undersea Biomed Res 1991; 18: 103-109.

3. Thorsen E, Segadal K, Myrseth E, Påsche A, Gulsvik A. - Pulmonary mechanical function and diffusion capacity after deep saturation dives. Br J Ind Med 1990; 47: 242-247.

4. Watt S. - Effect of commercial diving on pulmonary function. Br J Ind Med 1985; 42: 59-62.

5. Davey IS, Cotes JE, Reed JW. - Relationship of ventilatory capacity to hyperbaric exposure in divers. $J \mathrm{Appl}$ Physiol: Respirat Environ Exercise Physiol 1984; 56: 1655-1658.

6. Thorsen E, Segadal K, Kambestad B, Gulsvik A. Divers' lung function: small airways disease? $\mathrm{Br} J$ Ind Med 1990; 47: 519-523.

7. Thorsen E, Segadal K, Kambestad BK, Gulsvik A. Pulmonary function one and four years after a deep saturation dive. Scand J Work Environ Health 1993; 19: 115-120.

8. Clark JM. - Oxygen toxicity. In: Bennet PB, Elliott $\mathrm{DH}$, eds. The Physiology and Medicine of Diving. London, Balliere Tindall, 1982; pp. 200-238.

9. Thorsen E, Hjelle J, Segadal K, Gulsvik A. - Exercise tolerance and pulmonary gas exchange after deep saturation dives. J Appl Physiol 1990; 68: 1809-1814.

10. Dujic Z, Eterovic D, Denoble P, Krstacic G, Tocilj J, Gosovic S. - Effect of a single air dive on pulmonary diffusing capacity in professional divers. J Appl Physiol 1993; 74: 55-61.

11. Hlastala MP, Robertson HT, Ross BK. - Gas exchange abnormalities produced by venous gas emboli. Respir Physiol 1979; 36: 1-17.
12. Quanjer $\mathrm{PhH},(\mathrm{Ed}) . \quad-$ Standardized lung function testing. Bull Eur Physiopathol Respir 1983; 19 (Suppl. 5): $7-10$.

13. National Heart and Lung Institute. - Suggested standardised procedures for closing volume determinations (nitrogen method). Bethesda, Division of Lung Diseases, National Heart and Lung Institute, 1973.

14. Clark JM, Lambertsen CJ. - Pulmonary $\mathrm{O}_{2}$ toxicity: a review. Pharmacol Rev 1971; 23: 37-133.

15. Harabin AL, Homer LD, Weathersby PK, Flynn ET. An analysis of decrements in vital capacity as an index of pulmonary oxygen toxicity. J Appl Physiol 1987; 63: 1130-1135.

16. Spencer MP, Clark HF. - Precordial monitoring of pulmonary gas embolism and decompression sickness. Aerosp Med 1972; 43: 762-767.

17. Maio DA, Fahri LE. - Effect of gas density on mechanics of breathing. J Appl Physiol 1967; 23: 687-693.

18. Leith DE, Bradley M. - Ventilatory muscle strength and endurance training. J Appl Physiol 1976; 41: 508516.

19. Calder IM, Sweetnham K, Chan KK, Williams MMR. - Relation of alveolar size to forced vital capacity in professional divers. Br J Ind Med 1987; 44: 467469.

20. Kumar KV, Calkins DS, Waligora JM, Gilbert JH, Powell MR. - Time to detection of circulating microbubbles as a risk factor for symptoms of altitude decompression sickness. Aviat Space Environ Med 1992; 63: 961964.

21. Perkett EA, Brigham KL, Meyrick B. - Continuous air embolization into sheep causes sustained pulmonary hypertension and increased pulmonary reactivity. Am J Pathol 1988; 132: 444-454.

22. Clark JM, Jackson RM, Lambertsen CJ, Gelfand R, Hiller WDB, Unger M. - Pulmonary function in men after oxygen breathing at 3.0 ATA for 3.5 hours. J Appl Physiol 1991; 71: 878-885. 